\title{
A CRIAÇÃO DO TRIBUNAL PENAL INTERNACIONAL: Um meio para efetivar a proteção dos Direitos Humanos em âmbito internacional $^{1}$
}

\author{
Larissa Nunes Cavalheiro ${ }^{2}$ \\ Luiz Aristeu dos Santos Filho ${ }^{3}$ \\ Fernando Hoffmam ${ }^{4}$ \\ Franciele da Silva Câmara ${ }^{5}$
}

\begin{abstract}
Resumo: No atual contexto mundial, verificam-se conflitos que transgridem Direitos Humanos, originados de diversos motivos, desde questões de credo religioso até o terrorismo. Independente das motivações, a maior vítima acaba sendo o próprio homem, que tem seus direitos extirpados. Da preocupação em estabelecer uma justiça criminal, surge o Tribunal Penal Internacional (TPI), trazendo per se a função de realizar julgamentos justos e imparciais. A sua existência se configura em um importante marco para que se possa efetivar a proteção dos Direitos do Homem em âmbito mundial, pois visa punir aqueles que cometem os crimes previstos no Estatuto de Roma. O presente trabalho visa explanar acerca dos aspectos mais importantes do referido Tribunal, iniciando pelos seus antecedentes e chegando à sua criação. Passado esse momento, argumenta-se no sentido do seu caráter protecionista dos Direitos Humanos.

Palavras-chave: Tribunal Penal Internacional. Direitos Humanos. Julgamento. Proteção.
\end{abstract}

\section{THE CREATION OF THE INTERNATIONAL CRIMINAL COURT:} Considerations about the Court that could provide the international protection of the Human Rights

\begin{abstract}
There are conflicts that violate Human Rights, from a variety of reasons: religious issues, terrorism and others. Regardless of the motivations, the biggest victim is the humanity who had their rights suppressed. Considering the necessity of an international criminal justice, there was created the International Criminal Court (ICC), to perform a fair and impartial trial. Its existence represents an important starting point to the effective protection of the Human Rights in an international level, from the fact that this Court because it aims to punish those who commit the crimes that are defined in the Statute of Rome. The purpose of this paper is an explanation of its Court competence. First the paper focuses the history and the creation of this eminent international organization. After this, there is an issue about the character of this Court on the Human Rights protection.
\end{abstract}

KEYWORDS: International Criminal Court. Human Rights. Trials. Protection.

\footnotetext{
${ }^{1}$ Trabalho de pesquisa acadêmica em colaboração conjunta, desenvolvido pelo grupo por conta de atividades jurídicas envolvendo o tema.

2 Especializanda em Direito Público pela Escola Superior da Magistratura Federal e em Educação Ambiental pela Universidade Federal de Santa Maria; bacharel em Direito pelo Centro Universitário Franciscano. Advogada. E-mail: laranunes7@ hotmail.com.

${ }^{3}$ Mestrando em Ciências Sociais pela Universidade Federal de Santa Maria; bacharel em Administração, Ciências Sociais e licenciado em Sociologia pela Universidade Federal de Santa Maria. Bacharel em Direito pelo Centro Universitário Franciscano. Advogado. e-mail: luizaristeufilho@bol.com.br.

${ }^{4}$ Bacharel em Direito pelo Centro Universitário Franciscano. e-mail: ferdhoffa@yahoo.com.br.

${ }^{5}$ Especializanda em Gestão Pública Municipal pela Universidade Federal do Rio Grande do Sul; bacharel em Direito pelo Centro Universitário Franciscano. e-mail: fran_justitia@ hotmail.com.
} 


\section{INTRODUÇÃO}

Apesar de todo o estágio atual de desenvolvimento, a história da humanidade é marcada por um número considerável de guerras. Além delas, há também alguns dos momentos mais terríveis, configurados como crimes de extermínio e massacre étnicos. Afora as naturais relações conflitivas entres os seres humanos, a história tem mostrado que o flagelo da violência é algo que ainda existe e cujos efeitos nocivos se espraiam pelo mundo. Porém, é necessário que o homem olhe para trás, de forma a buscar evitar esse cruel destino manifesto.

O cenário de atrocidades do passado, cometidas nas duas grandes Guerras Mundiais, bem como em outros conflitos de menor escala, ainda permeiam a memória da humanidade nos dias atuais. Foram momentos de inúmeras violações dos Direitos do Homem. Em alguns casos, há que se lembrar, porém, que nem mesmo havia alguma proteção frente às barbáries cometidas no período de guerras.

Diante de um momento de total desrespeito a Dignidade da Pessoa Humana, durante a ascensão bélica do nazismo, na II Guerra Mundial, surgiu, em sentido contrário, um movimento de oposição pautado pelo anseio pela paz. Mesmo que durante aquela guerra aqueles crimes e violações cometidas tivessem inserido na população do mundo o sentimento de que a paz mundial tão almejada parecia estar sendo enterrada nos Campos de Concentração. A tortura, o sofrimento e a morte alcançavam todos aqueles entendidos como ameaças a um Imperialismo Nazista, motivado pela criação de uma raça branca, pura e superior.

Para o bem da humanidade, o Nazismo não alcançou seu objetivo maior. Contudo, deixou marcas na história que jamais serão esquecidas devido ao contexto de horror e ódio do homem contra o seu semelhante. Após esse período sombrio, surge então, a pretensão em estabelecer uma Justiça Criminal Internacional suficientemente isenta para resguardar os Direitos Humanos. Além disso, governada por uma efetividade que pudesse reprimir, em definitivo, os chamados Crimes Contra a Humanidade.

Com o avanço das Relações Internacionais e do ideal de cooperação entre os povos, surge o conceito de Responsabilidade Penal Individual Internacional. E, nesse sentido, torna-se igualmente necessário um órgão com competência para decidir os casos que podem ou não ser enquadrados nessa espécie de violação de direitos. Essa é a intenção delimitada quando se planejou a criação do instrumento conhecido como Tribunal Penal Internacional (TPI). Sua finalidade emerge de uma preocupação em 
assegurar a paz, a segurança e o bem-estar da humanidade, de forma que novas violações a esse direito coletivo não sejam admitidas internacionalmente.

Diante das atuais ameaças terroristas sofridas pela comunidade mundial, é matéria relevante a discussão sobre uma Jurisdição Penal Internacional. A pretensão do presente trabalho é elucidar as condicionantes históricas e jurídicas do referido Tribunal. Desse modo, busca-se demonstrar como sua convalidação representa a possibilidade do surgimento de um importante mecanismo de proteção dos Direitos Humanos, em escala mundial.

Para que uma análise nesses termos possa ser efetivada, a discussão proposta é dimensionada por meio de três distintas perspectivas. Inicialmente, observam-se as condicionantes históricas, bem como os tribunais internacionais que precederam a criação do TPI. Em um segundo momento, analisa-se a própria criação do TPI e suas delimitações legais. Um terceiro momento evidencia como o TPI pode ser analisado como uma condição de possibilidade para a efetivação dos Direitos Humanos.

\section{ANTECEDENTES HISTÓRICOS}

A ideia da criação de um órgão jurisdicional internacional não é nova. Ela se inicia com a própria formação dos Estados nacionais. Nesse sentido, convém lembrar que a noção de Estado-Nação envolve "[...] uma comunidade humana que pretende, com êxito, o monopólio do uso legítimo da força física dentro de um determinado território." (WEBER, 1982, p. 98) Para Rossato, Rossato e Rossato essa lógica de atuação estatal é baseada no monopólio da autoridade e da violência.

Atuando segundo essa perspectiva, o Estado "Comporta: $1^{\circ}$. uma racionalização do direito com a especialização do poder legislativo, judiciário e de política, para proteger a segurança dos indivíduos; $2^{\circ}$. uma administração racional com regulamentos explícitos que lhe permitam intervir em todos os domínios (educação, saúde, economia, cultura); $3^{\circ}$. força física militar permanente." (ROSSATO, ROSSATO e ROSSATO, 2006, p. 84). Essa é uma conformação de cunho westphaliano. O que, como indica Seitenfus, pauta-se na proposição do território, como determinante da soberania, uma vez que "O princípio da territorialidade levou o espaço físico a transformar-se em espaço jurisdicional sob a autoridade estatal. Encontrava-se o fundamento do Estado moderno pela identificação de sua base territorial. A linha de fronteira - linear, precisa, 
visível, intangível e inconteste - estabelecia o limite espacial onde seria exercida, com exclusividade a soberania. (SEITENFUS, 2004, p. 31)

Identificando igualmente as fronteiras como delimitadoras, porém, contendo um duplo vértice está Habermas (2001). O autor afirma que primeiro há um reconhecimento interno, que imprime no cidadão o respeito ao Estado como legitimado para criar a legislação que regula a vida naquele território. Depois, há um reconhecimento externo, que garante ao aparato estatal uma "exclusividade de mando", que o torna autônomo em relação aos demais, dispensando, em tese a preocupação com ataques externos.

Essa é uma preocupação, como indica Santos Filho, descende do Tratado de Westphalen. Caracteristicamente o referido tratado resguardava apenas a autonomia interna.

Isso ocorre pois a "Paz de Westphalen" enquanto criou uma estabilidade interna, calcada no Estado, criou uma "instabilidade estável". A "estabilidade instável" se refere à idéia da paz dentro das fronteiras territoriais, visto que o poder estatal era internamente incontestável. No entanto, sem a existência de um mecanismo de proteção externo, regulador das relações internacionais, apenas a crença no não-ataque mútuo e existência de alianças entre vizinhos garantiam a não-invasão mútua e defesa contra inimigos comuns. Isso perdurou até a criação da Liga das Nações, que auxiliou no sepultamento dessa insegurança. A liga foi substituída pela $O N U$, que até recentemente, quando da declaração da nova guerra do Iraque, era garantia suficiente ao direito da não-invasão estatal. (SANTOS FILHO, 2008, p. 10)

Porém, antes que esse período de "estabilidade instável" estivesse terminado, a humanidade ainda seria exposta a alguns conflitos, sem que pudesse a sociedade internacional oferecer mecanismos capazes de coibir crimes contra a humanidade. Após a II Guerra Mundial, porém, alguns Tribunais Internacionais foram criados para julgar os responsáveis por esses crimes.

$\mathrm{Na}$ perspectiva histórica, considerando-se o marco exposto, identifica-se o Tribunal de Nuremberg como um primeiro movimento nessa direção. Por meio dele foram julgados os crimes cometidos durante a II Guerra, pelos países do Eixo, derrotados pelos Aliados. Após esse primeiro movimento de criação e interpelação judicial, destaca-se também os Tribunais de Ruanda e da Ex-Iugoslávia. Todos estes constituem-se importantes precedentes para a criação do TPI.

No que diz respeito ao primeiro, Nuremberg foi cenário para o julgamento dos principais criminosos da Segunda Guerra Mundial, responsáveis pelo Regime Nazista. 
Esse tribunal foi criado por um acordo assinado pelos representantes dos E.U.A., GrãBretanha, França e U.R.S.S., em Londres, em agosto de 1945.

Alguns sustentam que na corte em Nuremberg aconteceu uma justiça parcial num tribunal de exceção criado pelos vitoriosos, e que existem inúmeras razões para duvidar dos critérios usados. O próprio rol de acusados é contestado, como também o fato de os acusados estarem sendo julgados por violar as leis internacionais, muito embora tais leis tenham sido criadas por Estados e não por indivíduos e após já haverem ocorrido todos os fatos. Muitos são da opinião de que os acusados deveriam ser julgados com as leis de seus próprios países e não em julgamento fundamentado em uma ordem instituída depois da guerra (CALETTI, 2002, s.p.).

A crítica que se fez ao julgamento em Nuremberg é quanto à imparcialidade. Uma vez que esse Tribunal foi criado pelos "vitoriosos", ensejando desconfianças quanto aos critérios usados. Seu caráter foi transitório e, por ser uma corte militar, julgou organizações e pessoas responsáveis pelas transgressões em amplo território.

Na instituição do Tribunal o princípio do Direito Penal nullum crimen nulla poena sine lege foi completamente esquecido, como também foi esquecido que no Direito Internacional a responsabilidade é do Estado e não das pessoas. Embora os vencedores também tivesse cometido crimes durante a guerra nenhum deles foi julgado e há quem sustente que os atos praticados pelo alemães eram só ilícitos e não criminosos (CALETTI, 2002, s.p.).

Os Tribunais estabelecidos para Ex-Iugoslávia e Ruanda, foram criados pelo Conselho de Segurança da ONU, para julgar apenas indivíduos que cometeram crimes contra a humanidade. Ambos foram cortes internacionais civis, formadas para o julgamento de ilícitos dentro de determinado território. Seus Estatutos não previam definições para as punições dos delitos, ficando a critério do juiz, e com isso, flagrante o desrespeito ao Princípio da Individualização da Pena (CALETTI, 2002).

Frente às falhas e críticas feitas a esses Tribunais Internacionais, emerge a necessidade de uma Corte com caráter permanente e independente, pois, como visto, os acima citados foram transitórios e vinculados a Estados ou a um Organismo Internacional. "Outra crítica assaz contundente voltada aos tribunais ad hoc - que já se ouvia desde a criação do Tribunal de Nuremberg - era no sentido de que os mesmos violavam regra basilar do direito penal, segundo o qual o juiz, assim como a lei, deve ser preconstituído ao cometimento do crime e não ex post facto” (MAZZUOLI, 2007, p. 744). 
Portanto, preocupados em criar um Tribunal que estabelecesse um julgamento mais próximo da justiça, tanto para os que sofreram como para os que cometeram os crimes contra a humanidade, surge então o Tribunal Penal Internacional. Esse é o assunto do próximo capítulo.

\section{A CRIAÇÃO DO TPI}

Feita essa breve explanação acerca dos antecedentes do TPI, cabe ressaltar os elementos de sua criação. Embora desde a II Guerra Mundial haja o ideal de um tribunal com jurisdição internacional, o mesmo só foi criado, de forma efetiva e permanente no ano de 1998. No dia 17 de julho de 1998, em Roma, concretiza-se a idéia de uma corte penal permanente. Nesse momento surge o TPI, sendo uma alternativa para se realizar um julgamento justo e afastar os procedimentos imprecisos dos até então conhecidos Tribunais Internacionais.

No que se refere especificamente ao momento da sua criação, o mesmo Lewandowski informa, mencionando o instrumento legal para a definição do TPI que, embora superada a fase militar de violações estatais dos direitos humanos, o Brasil assinou o pacto. Assim comenta o autor sobre o tema:

TRATADO DE ROMA, que prevê a criação do Tribunal Penal Internacional vinculado à Organização das Nações Unidas (ONU), foi aprovado em 17 de julho de 1998 por uma maioria de 120 votos a favor, 7 em contrário (da China, Estados Unidos, Filipinas, Índia, Israel, Sri Lanka e Turquia) e 21 abstenções. No dia 11 de abril de 2002, o Tratado alcançou 66 ratificações, ultrapassando o número de adesões exigido para sua entrada em vigor. O Brasil assinou o pacto em 12 de fevereiro de 2000, ratificando-o em 12 de junho de 2002, depois de aprovado pelo Congresso Nacional, tornando-se o $69^{\circ}$ Estado a reconhecer a jurisdição do TPI. (LEWANDOWSKI, 2002, p. 187)

No que se refere à estruturação do TPI dentro do instrumento, ele está assim delimitado, conforme Sgarbosa; Jensen:

O Estatuto de Roma divide-se em treze capítulos, os quais versam sobre a criação da Corte (Cap. I), sua competência, a admissibilidade e o direito aplicável (Cap. II), Princípios Gerais de Direito Penal (Cap. III), composição e administração do TPI (Cap. IV), inquérito e procedimento criminal (Cap. V), julgamento (Cap. VI), penas (Cap. VII), recurso e revisão (Cap. VIII), cooperação internacional e auxílio judiciário (Cap. IX), execução da pena 
(Cap. X), Assembléia dos Estados-partes (Cap. XI), financiamento (Cap. XII) e cláusulas finais (Cap. XIII). (SGARBOSSA; JENSEN, 2006, s. p.)

Com referência à estrutura administrativa do TPI prevista no Estatuto de Roma, ela é delimitada por força do art. 34 do citado dispositivo legal:

O Tribunal será composto pelos seguintes órgãos:

a) A Presidência;

b) Uma seção de recursos, uma secção de julgamento em $1 .{ }^{a}$ instância e uma seção de instrução;

c) $O$ Gabinete do Procurador;

d) A Secretaria. (MAZZUOLI, 2008, p. 1175)

Por meio dessa estrutura administrativa, cria-se o primeiro tribunal penal permanente, com competência para punir a responsabilidade penal individual, incluindo de chefes de Estado que tenham cometido os crimes previstos no Estatuto. Definem-se os princípios e garantias processuais, pressupostos para um julgamento nos moldes do devido processo legal.

O Tribunal tem competência subsidiária em relação às jurisdições nacionais de seus Estados-partes. Desde o preâmbulo do Estatuto já ficou proclamada a intenção dos Estados em criar um Tribunal Penal Internacional, de caráter permanente e independente, no âmbito do sistema das Nações Unidas, complementar das jurisdições penais nacionais, com competência para processar e julgar indivíduos acusados de cometer os crimes de maior gravidade que afetam a sociedade internacional como um todo (MAZZUOLI, 2007, p. 747).

O Estatuto afirma a intenção de auxiliar na prevenção e repressão dos mais graves abusos e violações dos direitos humanos. Além do seu caráter complementar, o TPI estabeleceu o Princípio da responsabilidade penal individual, “[...] segundo o qual o indivíduo responde pessoalmente por seus atos, sem prejuízo da responsabilidade do Estado [...]" (LEWANDOWSKI, 2002). Seus 128 artigos pretendem, então, evitar a impunidade a partir da consolidação da responsabilidade penal internacional do indivíduo.

Para não mais haver críticas quanto à soberania estatal para julgar os seus nacionais, ficou estabelecido para o TPI o Princípio da Complementariedade. Segundo o referido princípio, “[...] o TPI não pode interferir indevidamente nos sistemas judiciais nacionais, que continuam tendo a responsabilidade primária de investigar e processar os 
crimes cometidos pelos seus nacionais, salvo nos casos em que os Estados se mostrem incapazes ou não demonstrem efetiva vontade de punir seus criminosos." (MAZZUOLI, 2007, p. 747).

O Tribunal opera de forma complementar aos órgãos judiciais nacionais. Ou seja, só haverá atuação do TPI se verificada a inépcia ou falta de disposição dos Estados signatários de processar os seus nacionais. Interessante é notar que, embora não houvesse órgão internacional com tais poderes, havia uma previsão constitucional no ordenamento jurídico brasileiro para a subordinação ao mesmo. Nota-se que, "A própria Constituição da República Federativa do Brasil de 1988, em seu texto original, já aderira à idéia da criação de um Tribunal Penal Internacional, dispondo expressamente que "o Brasil propugnará pela formação de um tribunal internacional dos direitos humanos." (Ato das Disposições Constitucionais Transitórias, art. $7^{\circ}$ ).” (SGARBOSSA; JENSEN, 2006, s. p.)

No que se refere à sua jurisdição, esta se dá em razão da matéria. Assim sendo, ela envolve, nos termos do art. $5^{\circ}$ do tratado citado, a ocorrência daqueles "[...] crimes mais graves, que afetam a comunidade internacional no seu conjunto." (MAZZUOLI, 2008, p. 1162) Entre os crimes de sua competência estão o genocídio, os crimes contra a humanidade, os crimes de guerra e os crimes de agressão. E essa jurisdição, ressalte-se não vai além do aprovado na Conferência de Roma e daquilo que foi estabelecido no Estatuto.

O projeto base do Estatuto enumerava infrações de categorias distintas. A primeira dessas categorias ficou conhecida como core crimes, que consistia, basicamente, em um conjunto de delitos primordiais e elementares, quais sejam, genocídio, crimes contra a humanidade, crimes de guerra e crime de agressão. Estes crimes, ao final da conferência de Roma, foram incorporados ao Estatuto da Corte, dando origem aos artigos $5^{\circ}$ a $8^{\circ}$, responsáveis por descrever a competência material do Tribunal (OLIVEIRA, 2009, p. 30583059).

Da necessidade de um Tribunal Internacional permanente e independente, surgiu então o TPI. Com os crescentes conflitos internacionais, é de suma importância, aclarar a sua necessidade. Com isso, espera-se, dadas as condicionantes de análise, observar (ou mesmo atribuir-lhe) um caráter de elemento de proteção dos Direitos Humanos em âmbito internacional. Está será a análise do próximo capítulo. 


\section{O TPI E A PROTEÇÃO DOS DIREITOS HUMANOS}

No presente item, observa-se o TPI como uma provável condição de possibilidade para a efetivação dos Direitos Humanos. De início, no que se trata dessa questão, deve-se ressaltar que conforme o art. $1^{\circ}$ da Declaração Universal dos Direitos Humanos, “[...] todas as pessoas nascem livres e iguais em dignidade e direitos. São dotadas de razão e consciência e devem agir em relação umas às outras com espírito de fraternidade." (MAZZUOLI, 2008, p. 774).

Além disso, preocupação semelhante é expressa na Declaração Americana dos Direitos e Deveres do Homem, de 1948. Por meio dela se reconheceu que "[...] em repetidas ocasiões, os Estados americanos reconheceram que os direitos essenciais do homem não derivam do fato de ser ele cidadão de determinado Estado, mas sim do fato dos direitos terem como base os atributos da pessoa humana" (MAZZUOLI, 2008, p. 809).

No estágio atual do desenvolvimento da humanidade, os direitos de uma pessoa, bem como as prerrogativas fundantes da cidadania são compostas por ideias e expectativas. A maior delas envolve a proteção dos indivíduos contra qualquer um que queira impedir o exercício pleno de seus direitos. Para Bobbio (2004), o problema atual do direito, em especial dos Direitos Humanos, envolve não só a afirmação de que um indivíduo pode ser sujeito de direitos, visto que a criação de leis sempre é possível. $\mathrm{O}$ problema verdadeiro, na situação atual, é antes a efetivação daqueles direitos que atualmente encontram suporte no Ordenamento Jurídico criado pelo Estado. Especialmente quando esse mesmo Estado é o agente ou o instrumento que torna possível essa violação. Na história relacionada às grandes Guerras Mundiais e conflitos posteriores, a dignidade, a liberdade e a igualdade muitas vezes foram excluídas da vida do homem.

E, em alguns casos, o próprio Estado deu suporte a essa violação, seja como agente direto da violação, seja por não oferecer os instrumentos jurisdicionais adequados à resolução do problema enfrentado. As declarações citadas nos parágrafos precedentes reforçam o intuito de proteger e assegurar o efetivo exercício, pelos cidadãos, dos Direitos Humanos a eles inerentes. Além disso, se baseiam na percepção de que violações nesse sentido encontraram sua própria tipificação dentro da estrutura jurídica local, do Estado membro. 
Ao mesmo temo, reforça a importância de estruturas internacionais nesse mesmo sentido, dada a busca pela efetiva erradicação dos crimes internacionais mais violentos. Principalmente considerando-se os princípios que regem a proteção internacional dos Direitos Humanos, em particular o fato de se tratarem de estruturas dotadas de Complementaridade. Com a criação do TPI, passa-se a dispor de um amparo internacional prático, uma vez que este visa julgar aqueles que cometem os crimes mais violadores daquela espécie, dimensão ou geração de direitos.

A natureza objetiva da pretensão, ou matéria controvertida da lide, representa o critério de fixação da competência material. E, com o intuito de reprimir os perpetradores das mais atrozes violações de vida, paz e segurança internacionais são consagrados como bens jurídicos a serem universalmente tutelados, implicando o reconhecimento de infrações internacionais passíveis de afetar a comunidade global devido a sua maior gravidade (OLIVEIRA, 2009, p. 3058).

A agressão a esses direitos é crescente, nos variados conflitos vistos na atualidade. Por motivo territorial, étnico, religioso, entre outros, se constrói um palco no qual indiscriminadamente se ferem os direitos do homem. Trata-se de uma situação vergonhosa com a qual a humanidade precisa conviver, mas que, ao mesmo tempo, deve ser evitada, uma vez que disputas de poder não deveriam governar uma sociedade pautada pela razão e pelo ideal de convivência com respeito recíproco, que se forma internacionalmente.

Com as negativas experiências do passado, não se pode mais tolerar a agressão a esses direitos. Afinal, uma vez que se abra margem a isso, corre-se o risco de se viver novamente um dos momentos mais sombrios na história da humanidade. E é justamente dessa vontade internacional de minimizar a probabilidade de ocorrência de novos massacres étnicos, bem como novas violações maciças de direitos, apoiadas pelas estruturas estatais, que ressalta-se a importância do TPI:

Nessa perspectiva, e diante nas violentas agressões que os direitos humanos têm sofrido, na maioria das vezes sem qualquer responsabilização criminal, é que se faz imprescindivel a implementação de um tribunal penal internacional, de caráter permanente e autônomo, de molde a prevenir qualquer forma de vilipêndio ao direito e humanitário, bem como dissuadir que os potenciais transgressores das normas de direito internacional pratiquem atos atentatórios à existência digna do homem (FURTADO apud ABREU, 2002, p. 6) 
Com o advento do Tribunal Penal Internacional, surge um importante instrumento para estabelecer a salvaguarda desses direitos. "A rigor, a maior justificativa para a criação dos tribunais internacionais assenta-se no princípio jusnaturalístico da dignidade da pessoa humana, pedra angular do direito humanitário. E é em busca da preservação dos direitos humanos, por meio de uma jurisdição universal, que se tem reestruturado a tão arraigada idéia de soberania” (ABREU, 2002, p.5).

Como já explanado, esse Tribunal é apto para punir aqueles que possivelmente passariam impunes pelas jurisdições nacionais, ou nem mesmo seriam julgados. Cria-se, por meio dele, uma forma, um verdadeiro mecanismo jurídico de repressão desses crimes, em âmbito mundial. Principalmente considerando-se que este Tribunal é um mecanismo que vem garantir a punição, reprimindo futuros violadores dos Direitos Humanos em esfera supranacional. Desempenha verdadeira revolução, à medida que, por meio dele se pode punir não apenas o Estado em si, mas a pessoa do verdadeiro causador do crime.

É claro que uma discussão nesse nível, gera divergências. Porém, é preciso elencar duas questões fundamentais que são ressaltadas, quando do tratamento do tema. Em especial, no que se refere à soberania dos Estados, questão que deu abertura ao presente artigo. Em uma análise mais apressada, poder-se-ia intuir que a presença de um tribunal com jurisdição e posição nos termos do TPI serviria como elemento que impediria a manutenção da soberania.

No entanto, essa posição não é de todo verdadeira. E isso fica evidente quando se observa a tese principal defendida por Bodin. Segundo sua percepção de sobnerania, há um único centro de decisão. Porém, isso não quer dizer que funções não essenciais de comando não possam ser delegadas, como indica Barros (1995). E, desse modo, pode o ideal de Estado se manter, de modo autônomo em relação ao Governo.

Além do mais, há que ficar claro que, mesmo se tratando de crimes da competência do TPI, ressalta-se dispositivo pátrio por meio do qual se estabelece, nas palavras de Piovesan, que “[...] na hipótese de eventual conflito entre o Direito Internacional dos Direitos Humanos e o direito interno, adota-se o critério da prevalência da norma mais favorável à vítima. Em outras palavras, a primazia é da norma que melhor proteja, em cada caso, os direitos da pessoa humana." (PIOVESAN; GOMES, 2000, p. 30). 
Assim, vê-se que ao mesmo tempo em que se cria um órgão jurisdicional internacional, está-se respeitando a soberania de cada Estado membro. Ao mesmo tempo, está-se diante de mecanismo de efetiva proteção dos Direitos do Homem. Uma questão que, na sociedade atual, em que se pode e precisa-se respeitar culturas e características diversas das populações, pode-se plenamente efetivar esse fruto das lutas históricas travadas na supressão de violações de direitos praticadas dentro e pelo próprio Estado.

\section{CONSIDERAÇÕES FINAIS}

Os Direitos Humanos representam uma verdadeira luta pela ascensão do homem a um novo patamar. Sua proteção, assim sendo, se torna das mais relevantes, dadas as condições atuais da sociedade. O que torna ainda mais relevante a existência de um órgão com jurisdição internacional, versando acerca da proteção contra crimes de elevado reflexo, o que pode ser implementado por força da criação de um tribunal internacional.

A evolução dos Tribunais Internacionais evidencia uma crescente preocupação em se chegar a processo imparcial, comprometido com os princípios de uma justiça penal, bem como com a efetiva punição dos responsáveis pelos crimes cometidos. A partir do julgamento de Nuremberg, passando por Ruanda e Ex-Iugoslávia, formaram-se alguns tribunais penais importantes, dado o seu cunho internacional, mas que ainda não eram plenamente garantidores de um julgamento justo. Porém, o direito a um julgamento justo deve ser assegurado, mesmo diante de terríveis atrocidades cometidas pelos acusados.

Dessa forma, pensando nas garantias e direitos de um processo penal livre de falhas e críticas, chegou-se a criação do Tribunal Penal Internacional, sendo dito tribunal regrado por força do Estatuto de Roma. Como o mesmo possui caráter permanente, em primeiro lugar já se está garantindo a imparcialidade do julgamento, pois se trata de um Tribunal Internacional estabelecido para julgar apenas os fatos posteriores a sua criação. Diferentemente daqueles que foram criados no passado, que eram constituídos apenas após o fato delituoso, fato que sempre trouxe consigo certa desconfiança, no que se refere ao seu significado, vez que os julgamentos eram realizados pelos "vencedores" dos conflitos. 
Também se considera importante avanço a adoção do Princípio da Responsabilidade Criminal Individual. Segundo este, além do Estado transgressor, o indivíduo que promoveu essa violação de direitos não passará impune e será responsabilizado, caso sua conduta seja enquadrada entre os crimes previstos naquele Estatuto. Além disso, diferentemente daqueles tribunais que o precederam, os países que se submetem ao TPI, devido a sua jurisdição complementar, não têm sua soberania relativizada, quanto aos julgamentos realizados. Isso ocorre uma vez que o tribunal referido, só atuará na ausência de elementos e instrumentos que garantam a manifestação judiciária do Estado membro do Tratado de Roma.

Da análise dos aspectos mais importantes do Tribunal Penal Internacional, verifica-se a possibilidade deste ser um instrumento de repressão as agressões aos Direitos Humanos em âmbito global. Na atualidade, existem conflitos reprováveis pelas consequências extremamente violadoras dos Direitos do Homem. Assim, se faz necessário a existência de um Tribunal como o TPI e sua adoção por mais países, para dessa forma, surgir uma justiça penal internacional.

Diante disso, e adotando essa internacionalização do Direito como um parâmetro essencial de um mundo globalizado, surge a ideia de uma justiça penal internacional, amparada no TPI, como uma busca pela garantia e pela salvaguarda dos Direitos do Homem. Da existência desse tribunal, juntamente, surge a segurança de um processo desvinculado de qualquer parcialidade e sim, comprometido com um julgamento efetivamente justo. Afasta-se assim a impunidade dos violadores dos Direitos Humanos, assegurando a prevenção e importância desses a todos, em esfera mundial. E isso representa sobremaneira a efetivação necessária a essa categoria de direitos.

\section{REFERÊNCIAS BIBLIOGRÁFICAS}

ABREU, Luís Marcelo. Uma análise do Tribunal Penal Internacional e da sua efetividade perante a Constituição brasileira. Buscalegis. Florianópolis, 17 jul. 2006. Disponível em: <http://www.buscalegis.ufsc.br/revistas/index.php/buscalegis/article/do wnload/12333/11897> Acesso em: 07 jan. 2010.

BARROS, Alberto Ribeiro. "Estado e governo em Jean Bodin". Revista Brasileira de Ciências Sociais, São Paulo, n. 27, p. 129-137, 1995. Disponível em: <http://www.anpo cs.org.br/portal/publicacoes/rbcs_00_27/rbcs27_08.htm>. Acesso em: 25 out. 2009. 
BOBBIO, Norberto. A era dos direitos. Nova ed. 5. a. reimpress. Rio de Janeiro: Elsevier, 2004.

CALETTI, Cristina. Os precedentes do Tribunal Penal Internacional, seu estatuto e sua relação com a legislação brasileira. Jus Navigandi, Teresina, ano 7, n. 64, abr. 2003. Disponível em: <http://jus2.uol.com.br/doutrina/texto.asp?id=3986>. Acesso em: 02 fev. 2010.

HABERMAS, Jürgen. A constelação pós-nacional: ensaios políticos. São Paulo: Littera Mundi, 2001.

LEWANDOWSKI, Enrique Ricardo. O Tribunal Penal Internacional: de uma cultura de impunidade para uma cultura de responsabilidade. Estudos Avançados. 2002, vol.16, n.45, pp. 187-197. Disponível em <http://www.scielo.br/pdf/ea/v16n45/v16n45a12. pdf>. Acesso em: 07 fev. 2010.

MAZZUOLI, Valério de Oliveira. Curso de Direito Internacional Público. 2 ed. rev., atual. e ampl. São Paulo: Editora Revista dos Tribunais, 2007.

Coletânea de Direito Internacional. 6 ed. rev., ampl.e atual. São Paulo: Editora Revista dos Tribunais, 2008.

OLIVEIRA, Cristiano José Martins de. Os crimes internacionais e o Tribunal Penal Internacional: análise dos conceitos dos tipos penais do Estatuto de Roma. Acesso em: <http://www.conpedi.org/arquivos/anais/maringa/05_1656.pdf> Acesso em: 05 fev. 2010.

PIOVESAN, Flávia, GOMES, Luiz Flávio. O sistema interamericano de proteção dos direitos humanos e o direito brasileiro. São Paulo: RT, 2000.

ROSSATO, Ricardo; ROSSATO, Ermélio e ROSSATO Elisiane Rubin. As Bases da Sociologia. Santa Maria: Biblos, 2006. 
SANTOS FILHO, Luiz Aristeu dos. Um olhar sobre Burocracia, Maquiavelismo, Direito e Comédia: Jocosidade e Crítica à Eficiência Estatal em "O Guia do Mochileiro das Galáxias" de Douglas Adams. Santa Maria: Centro Universitário Franciscano, 2008.

SEITENFUS, Ricardo Antônio Silva. Relações Internacionais. Barueri: Manole, 2004.

SGARBOSSA, Luís Fernando; JENSEN, Geziela. As opções políticas do Estatuto de Roma e seu impacto em relação ao regime jurídico-constitucional dos direitos fundamentais no Brasil . Jus Navigandi, Teresina, ano 10, n. 1152, 27 ago. 2006. Disponível em: <http://jus2.uol.com.br/doutrina/texto.asp?id=8849>. Acesso em: 10 abr. 2010.

WEBER, Max. A política como vocação. In: GERTH, H. H. \& MILLS, Wright (orgs.). Max weber - ensaios de sociologia. 5. ed. Rio de Janeiro: LTC, 1982a. 